\title{
A CONDIÇÃO SEMIÓTICA DOS MUROS: análise a partir da psicanálise freudiana no estudo da interpretação dos sonhos
}

\author{
Tiago Mendes Filgueiras ${ }^{1}$
}

tiagomendes.arquitetura@hotmail.com

\begin{abstract}
Resumo
Este artigo aproxima o pensamento freudiano sobre o processo formador dos sonhos e as diversas possibilidades de sua análise, a uma reflexão a cerca do universo simbólico que o muro está inserido. Focando especificamente na metodologia por trás dos dois processos: o "trabalho de condensação" e o "trabalho de deslocamento", criados por Freud para explicar a formação dos sonhos, este escrito aborda os inúmeros significados que são incorporados ao muro por meio de sua inserção nas diversas culturas, em especial, a urbana. A metodologia definida passa pelas perspectivas históricas, semiológicas e estéticas, e tem como foco trazer a tona aspectos do muro que o tornam um elemento muito mais rico do que uma simples barreira.
\end{abstract}

Palavras Chave: sonhos; reflexão; muro; significados; barreira.

\begin{abstract}
This article takes the Freudian thought on the formation process of dreams and the diverse possibilities of its analysis to a reflection about the symbolic universe in which the wall is inserted. Focussing mainly on the methodology underlying these two processes, the "condensation work" and the "displacement work", created by Freudto explain how dreams are formed, this text approaches the countless meanings that are incorporated in the wall through to its insertion in many cultures, especially the urban. This defined methodology goes through historical, semiotic and aesthetic perspectives, and focuses on bringing out aspects of the wall that turn it into a much richer element than a simple barrier.
\end{abstract}

Keywords: dreams; reflection; wall; meanings; barrier.

\footnotetext{
${ }^{1}$ Graduado em Arquitetura e Urbanismo pela Pontifícia Universidade Católica de Goiás (2008). Mestrando em Arquitetura pelo Programa de Pós-graduação da Universidade de Brasília, iniciado em 2014. É membro do NEHS - Núcleo de Estética, Hermenêutica e Semiótica, grupo de pesquisa vinculado ao CNPq. Compõe a equipe editorial das revistas: Revista Estética e Semiótica (RES) e Paranoá: Cadernos de Arquitetura e Urbanismo.
} 
Inserido num estudo mais amplo sobre os muros, o presente texto tem como foco o pensamento de tal elemento por uma perspectiva semiológica, tendo como principal referência o texto de Sigmund Freud, A Interpretação dos Sonhos, em especial, dois conceitos centrais para o pensamento freudiano: o "trabalho de condensação" e o "trabalho de deslocamento" dos sonhos. Freud desenvolve suas ideias tendo como foco a criação de uma metodologia para a análise dos sonhos como um meio de análise da pisque humana. Entretanto, tal abordagem cria uma série de lacunas e contradições que são, de certa maneira, naturais em se tratando de sonho. Portanto, este texto busca compreender, não o resultado das pesquisas de Freud, mas o princípio de seu raciocínio, estabelecido nos dois movimentos que o pensamento realiza para a criação do sonho: condensação e deslocamento. Isto servirá para complementar o estudo sobre os muros e a sua relação com o homem, esclarecendo seu universo simbólico, imprescindível para a vivência urbana.

Antes de entrar propriamente nos dois conceitos apresentados, é importante deixar claro o modo com que Freud estabelece dois níveis envolvidos na criação dos sonhos: o relato incompleto, ou o chamado "conteúdo manifesto" e o pensamento do sonho, ou o chamado "conteúdo latente". A diferença básica é que, no conteúdo manifesto, estão presentes as imagens, sons ou palavras que chegam à consciência e são passíveis de recordação e consequente relato - o que já é uma interpretação - e sobre as quais as análises do sonho serão feitas. O outro nível de pensamento é o que se esconde por trás de cada signo relatado. De fato, para Freud, a razão da existência do sonho é justamente poder revelar ao consciente uma gama de pensamentos em que a censura imposta pelo superego impede. Assim, o conteúdo latente seria como o texto original sendo já uma interpretação - e o conteúdo manifesto seria como a tradução desde texto por meio de signos, e a tarefa de quem interpreta o sonho seria de, analisando as imagens e desvendando sua sintaxe, desvendar o texto original. Uma aproximação seria um quebra-cabeça conhecido como Rebus, ou Carta Enigmática, em que o jogador deve interpretar as imagens presentes no texto transformando-as em palavras que completem o sentido original.

O relato do sonho é apenas uma pequena parte do pensamento que o gerou, ou seja, o "conteúdo latente" é muito mais vasto e rico que as imagens que se apresentam no "conteúdo manifesto" do sonho. Surge então o primeiro paradigma desse raciocínio: 
o sonho nunca poderá ser completamente analisado. Ao passo que a análise de suas imagens se aprofunda, novas relações e significados podem aparecer resultando em uma impossibilidade de se chegar a uma verdade absoluta. Esse paradigma pode ser deslocado para a análise da semântica dos muros. Seria impossível determinar uma sintaxe precisa sobre a diversidade semiológica derivada da relação do homem com o muro, portanto defini-se aqui o limite dessa análise: não pretende fechar o universo semântico do muro, muito menos criar uma linguagem sobre a diversidade simbólica possível; este trabalho tem a intenção apenas de abrir o assunto e levantar hipóteses sobre essa relação simbólica: homem - muro.

Voltando ao trabalho do sonho, Freud compreende que por debaixo de cada imagem do sonho existe uma enormidade de pensamento. Isso quer dizer que, para a criação do sonho, deve existir o que ele chama de "trabalho de condensação", ou no original "Verdichtungsarbeit", que poderia ser traduzido também como "trabalho de 'compressão' ou 'adensamento'”. De qualquer maneira, a ideia que se quer passar é de que há no sonho um volume de pensamento comprimido ou condensado, o qual realmente interessa na esfera do consciente.

Ao se pensar na relação entre a análise dos sonhos e a ideia defendida aqui sobre os muros, é possível traçar certo paralelismo. Na maneira que Freud enxerga, o sonho funcionaria tanto como uma barreira quanto como um meio para se chegar ao pensamento inconsciente. Essa dualidade entre barreira e meio é o paradigma fundamental para a compreensão que está sendo proposta sobre o muro. O muro em si e as diferentes maneiras como é apresentado seriam como as imagens do sonho, que escondem por trás uma infinidade de significados e relações que são de fato importantes para a compreensão da apropriação do homem do espaço urbano. Portanto, uma analogia entre ambas as análises, dos sonhos e dos muros, se torna extremamente eficiente para auxiliar na elucidação do caminho a percorrer. Ao colocar o muro no papel do sonho, as demais relações são automaticamente feitas: a compreensão da maneira de como o homem vive a cidade desempenharia o papel do consciente, a censura seria interpretada pela ideologia arquitetônica criada ao longo do tempo e o subconsciente seria o universo relacional existente entre o cidadão e o muro, em que a barreira seria apenas mais um dos diversos conceitos possíveis para esse elemento. 
Nesse paralelo, assume-se a mesma tarefa que Freud assumiu: a de investigar as relações entre o conteúdo manifesto, ou seja, as diversas maneiras de como são apresentados os muros; e os pensamentos oníricos latentes, ou seja, as relações subjacentes escondidas por trás do conceito da barreira. A segunda parte dessa tarefa, que seria tentar desvendar os processos pelos quais os pensamentos oníricos latentes se transformam em sonhos, não faz parte dessa abordagem, pois a visão crítica que se tem é que residem aí as possíveis contradições e lacunas no pensamento freudiano. Qualquer tentativa de fechar a discussão em uma possível metodologia para a interpretação e análise, tanto dos sonhos, quanto dos muros, iria criar uma nova ideologia, voltando ao ponto inicial que instigou esta investigação. Entretanto, ao passo que as relações vão sendo abordas, é possível perceber a clara ligação entre uma determinada relação com a cidade e a necessidade que se teve em construir um muro.

Um bom exemplo dessa relação pode ser discutido por meio dos muros criados para cercar cemitérios. Essa questão remete às origens da cidade quando as primeiras configurações urbanas começaram a se desenvolver no que Lewis Mumford (MUMFORD, 1998) chama de "Cidade dos Mortos". Esse historiador coloca o cemitério como precursor da cidade primitiva. Em suas palavras "a cidade dos mortos anteviu a cidade dos vivos", na medida em que os homens daquele tempo, apesar de nômades, sempre voltavam ao mesmo local para enterrar seus mortos. Essa relação entre um determinado lugar e a morte expõe uma questão fundamental para o assunto que está sendo tratado: o sagrado. A morte representa uma condição fatídica ao ser humano e, em meio a sua consciência de ser mortal, torna a relação com o local do enterro algo extremamente simbólico. Nessas condições, o fato de se murar a "cidade dos mortos" deixa claro a postura que o ser humano assume diante de sua autoconsciência perene e frágil. Pode-se até mesmo pensar num aprofundamento ainda maior quanto à capacidade reflexiva desenvolvida ao longo da história humana. Valorizar os mortos seria a contrapartida factual de uma reflexão, por vezes inconsciente, da autopercepção. Assim sendo, o muro, no caso do cemitério, seria um dos símbolos da sacralização do espaço dos mortos, refletindo o entendimento metafísico desenvolvido ao longo do tempo.

Entretanto, apesar do cemitério ter antecipado a urbe tradicional, as primeiras aparições do muro na história ocidental da cidade deram-se justamente com a aparição 
das primeiras cidades. Aliás, a transformação urbana que possibilitou o surgimento das cidades foi a criação de um espaço fechado por muros. Ao longo do percurso histórico apresentado na obra A Cidade na História (MUMFORD, 1998) é possível perceber que o autor refere-se à muralha não apenas como uma fortificação de caráter estritamente militar, tal qual uma fortificação, mas sim como um elemento urbano fundamental na consolidação da urbe.

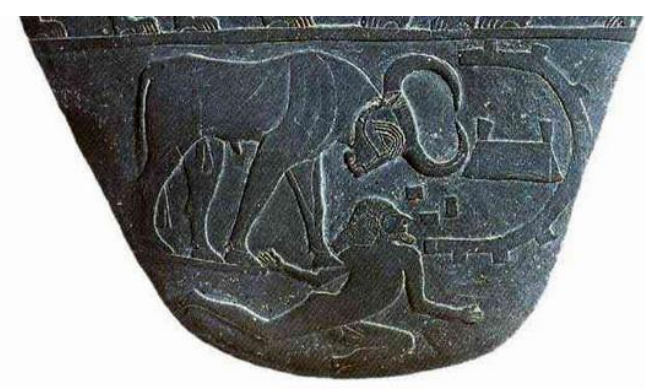

Imagem $n^{\circ} 1$. Detalhe da Paleta de Narmer

Disponível em: www.egiptoantiguo.org

Data: 20 de Maio de 2014

$\mathrm{Na}$ imagem temos, segundo Mumford, a primeira imagem de cidade na história. Aqui, o rei, sob a forma de um touro, espezinha uma cidade murada. (MUMFORD, 1998, p.145). O autor complementa o comentário com a seguinte afirmação:

Embora os egiptólogos geralmente chamem fortes a tais estruturas muradas, atribuindo-lhes as funções das fortalezas especializadas militares do Médio Império, há boas razões para supor que eram cidades, sobretudo porque sua forma corresponde ao hieróglifo redondo original de cidades. $\mathrm{O}$ recinto circular era, provavelmente, uma forma neolítica primitiva (maternal), antecipando as divisões retangulares (de orientação masculina) dos campos de cultivo. (MUMFORD, 1998, p.145-146)

Ao analisarmos a afirmação, percebemos importância da carga simbólica para a representação da cidade. A forma circular da muralha transmite a ideia da proteção materna. Logo podemos concluir que a estrutura murada sempre teve um forte peso na compreensão do espaço urbano desenvolvido e para a sensação de proteção de tal aglomeração humana. 
A necessidade de se criar um espaço protegido, tornando-o sagrado, provavelmente tenha sido o que motivou o surgimento da estrutura murada descrita. $\mathrm{O}$ caráter sagrado que defendemos está ligado ao fato da "sobre-vivência", ou seja, da tentativa de se tornar eterno, ou, nas palavras de Mumford, de defender os sagrados limites do têmenos e manter à distancia antes os maus espíritos do que os inimigos humanos. (MUMFORD, 1998,p.44).

O encerramento de um espaço circular pela estrutura murada, além do caráter sagrado, também levanta outra questão, a da relativização das formas de apreensão do muro por meio da compreensão de espaço interno e externo. Ao se refletir por essa perspectiva, podemos perceber uma série de implicações decorrentes ao simples posicionamento do observador. Estando do lado de dentro ou de fora, a pessoa pode percebê-lo como espaço sagrado ou como segregado, como um espaço protegido ou como encarcerado. A relação com o muro depende fundamentalmente de qual ponto de vista o estamos enxergando.

A perspectiva histórica nos deixa claro que, a partir do momento de seu surgimento, o muro se transformou em um símbolo de proteção e ainda mais, tornou-se signo de cidade - como na Paleta de Narmer. Ao longo do tempo o simbolismo do muro vem sendo alterado para cada momento da vida urbana. Talvez tenha sido com a abertura das cidades no século XVIII que a percepção do muro tenha mudado da perspectiva interna para a externa. A mudança na escala dos muros, passando de grandes muralhas para pequenos muros, cercando residências isoladas ou pequenos grupos de edificações dentro da malha urbana aberta, o transformou em um símbolo de segregação, uma barreira, ou aquilo que impede, deixando clara a questão do interno e externo. A função do muro deixou de ser a de proteger a cidade e passou a ser de proteger o cidadão, ou seja, a massa populacional não está mais dentro dos muros, mas fora deles.

O movimento que se pretende é, por meio de uma abordagem estética, chegar às simbologias associadas a esse elemento. Tal qual a análise das imagens do sonho resultam em uma análise semiológica, acredita-se que, partindo da condição que se percebe o muro, pode-se aproximar da análise conduzida por Freud. Portanto, ao realizar uma abordagem histórica, partindo de Lewis Mumford, chega-se à condição primária do muro enquanto barreira, elegendo a muralha medieval como o exemplo 
mais significativo. Tem-se como contrapartida mais recente à muralha o "Muro de Berlim", na Alemanha, o "Muro da Cisjordânia", entre a Cisjordânia e Israel, o "Muro Fronteiriço Estados Unidos-México", etc., em que a condição de limite é tão clara quanto. Nesses últimos casos, apesar do conceito de barreira estar presente, tal qual no exemplo da muralha, o aspecto simbólico é diferente. Enquanto no primeiro sua significação está ligada ao poder e a força de quem se protege, nos dois últimos exemplos, questões ligadas ao seu contexto histórico transformaram-nos em símbolos de segregação, de separação e de injustiça, já que o mesmo poder e força foram usados muito mais para isolar o outro, do que se proteger.

Cabe nesse ponto do texto introduzir uma metáfora importante no desenvolvimento das ideias sobre o tema: a sublimação do conceito da barreira. A percepção do muro enquanto barreira - conceito sedimentado, sólido e aparentemente definitivo - poderia sofrer uma espécie de sublimação ao ser incorporado de novas relações e significados. Tais significados incorporados teriam uma condição fugidia, esparsa e inconstante, podendo variar sua forma de entendimento, tal qual a transformação dos elementos pela sublimação. É importante salientar que a metáfora proposta pensa a sublimação apenas como o conceito físico, deixando de lado seus usos pela filosofia e pela psicanálise. Deste modo, a condição "gasosa" da percepção do muro se torna mais rarefeita ao passo que se aproxima da arte, compreendida como algo que não pode ser completamente percebido e em constante transformação adaptando-se às condições de seu meio; enquanto que o universo simbólico seria o instante em que o material é percebido tanto em estado gasoso quanto sólido. Ou seja, o esforço em se comparar o processo físico da sublimação com a forma de reflexão conduzida nesse texto divide a abordagem em três diferentes níveis: um estado sólido, um estado gasoso e um estado intermediário, em que estão presentes ambos; representados respectivamente pela função, pela estética e pela simbologia do muro. O estado sublimado das coisas guarda a sua essência enquanto sólido, e é assim a ideia defendida sobre o muro: apesar de sua percepção tornar-se rarefeita, o muro como objeto deve necessariamente estar presente. Diferentemente do conceito da barreira, que pode ser deslocado do muro - como, por exemplo, um limite não material como um grande espaço vazio ou uma marcação no solo -, a questão aqui presente traz o objeto físico como essa essência imutável, independente de sua forma de percepção. 
Tal metáfora parte do princípio encontrado na segunda parte do trabalho do sonho que Freud denomina "Trabalho de Deslocamento". Nesse processo, há um deslocamento ou um realojamento dos pensamentos oníricos na formação do sonho por meio de outros dois processos definidos como: transferência e deslocamento de intensidades psíquicas. Esses dois processos, inseridos no Trabalho do Deslocamento, atuam despojando os elementos com alto valor psíquicos de sua identidade e criando novos valores a elementos com baixo valor psíquico. De forma que o conteúdo manifesto presente no sonho possui os mesmos elementos do pensamento, mas representados de maneira distorcida ou até mesmo inversa. Segundo Freud, esse seria o principal processo na formação do sonho, sendo ele o responsável pela vasta gama no universo semiológico que dá ensejo para os estudos psicanalíticos.

Transferindo esses princípios psicanalíticos para o que se trata neste estudo, a sublimação do conceito da barreira é, de certa forma, um deslocamento dos valores tradicionais atribuídos ao muro, no caso o limite e a barreira, uma hierarquia em que os valores ligados à sua função ocupariam as posições mais baixas, enquanto os ligados à estética e a semiótica ocupariam os postos mais altos.A razão de todo esse esforço seria a de questionar, de maneira mais ampla, a ideologia presente nas teorias sobre a análise do ambiente urbano, em que questões sobre os significados dos elementos urbanos são tidas como verdade universal e em momento algum são postas em questão, resultando em uma ideologia no que Mario Gandelsonas e Diana Agrest definem em seu estudo sobre semiótica:

[...] A ideologia pode ser definida como um conjunto de representações e crenças - religiosas, morais, políticas, estéticas - a respeito da natureza, da sociedade, da vida e das atividades dos homens sobre a natureza e a sociedade. A ideologia tem a função social de manter a estrutura global da sociedade induzindo os indivíduos a aceitar em suas consciências o lugar e o papel que essa estrutura lhes designa. Ao mesmo tempo, a ideologia atua como um obstáculo ao verdadeiro conhecimento, impedindo a constituição da teoria e seu desenvolvimento. [...] A função da ideologia não é produzir conhecimento, mas opor-lhe obstáculos. [...] A soma de todo o "conhecimento" arquitetônico ocidental, das instituições do senso comum às complexas "teorias" e histórias de arquitetura, deve ser vista mais como ideologia do que como teoria. [...] (AGREST, Diana; GANDELSONAS, Mario 2006, 130-131) 
Os estudos das teorias lingüísticas em arquitetura, em especial a semiótica, fornecem outro embasamento teórico para a construção da ideia. A abordagem desses autores sobre os signos em arquitetura no seu texto "Semiótica e Arquitetura" defende uma visão desvinculada à semiótica tradicional onde os objetos no ambiente têm um significado inerente. Para os autores, esse tipo de abordagem semiótica aplicada de forma mecânica à arquitetura apenas favorece o bloqueio da produção de conhecimento arquitetônico, uma vez que reforça a função da ideologia arquitetônica.

Retomando o processo de sublimação do conceito de barreira pela abordagem histórica, todos os casos se aproximam exercendo sua função de limite, mas ao passo que suas simbologias são colocadas em questão há um distanciamento evidente, polarizado em dois aspectos: o positivo e o negativo. É importante salientar que essa polarização deve ser relativizada, pois é evidente que seus significados dependem de um ponto de vista: do protegido ou do encarcerado, do dominante ou do dominado, etc. Portanto, o "estado sólido" da simbologia dos muros está definido por dois vieses: um aspecto positivo, que poderia ser representado pela muralha medieval, o qual servia para a proteção da população urbana, e por outro lado, o viés negativo, representado pelos muros usados para segregar ou isolar povos.

Após ser esclarecida a condição "sólida" do muro, a semiótica e a estética serviriam para este estudo tais quais os catalisadores para o processo de sublimação. A semiótica, já evidente no primeiro momento, aborda o muro enquanto símbolo por diversos aspectos, sendo delimitado pelo conceito de "lugar antropológico" nas condições postas Marc Augé em seu livro Não Lugares (1992). Nessa perspectiva, se compreende o muro enquanto símbolo que constitui um lugar nos três seguintes aspectos: histórico, relacional e identitário. Um dos exemplos mais claros disto é o muro urbano de pequena escala, presente na paisagem urbana em boa parte das cidades atuais. Esse muro representa um lugar, nas condições postas, para as pessoas que vivenciam sua presença e percebem o espaço que ele cerca.

Além do muro de pequena escala, outro exemplo em que sua simbologia extrapola a função de barreira é o "Muro das Lamentações", em Jerusalém, Israel. Neste caso o "lugar antropológico" é construído pela relação com o sagrado. Talvez seja atualmente um dos casos em que se tenha o maior distanciamento entre a condição de barreira e seu real uso. Nesse caso, a própria função de objeto de culto religioso é 
desprendida do conceito direto barreira, tornando-se um artefato sagrado. Assim, a volatilização está manifestada de maneira mais notória e o "lugar antropológico" estabelecido de forma mais profunda.

No viés estético, equivalente ao estado integralmente gasoso, a tentativa é a de se perceber o muro como um objeto estético, em que a experiência em percebê-lo esteticamente é mais eficaz ao passo que seu uso é menos percebido. Ou seja, tanto mais o muro é percebido pela estética, tanto menos é reconhecido como barreira. Essa abstração completa do conceito de barreira é percebida com maior intensidade quando a arte passa a usar desse elemento físico como suporte, ou mais ainda, como matériaprima. Exemplos disso são os grafites sobre os muros. Nesses casos, a arte está tomando o muro como tela e também como suporte para a comunicação com os cidadãos. Um nível mais profundo dessa relação entre arte e muro pode ser percebido em certos artistas que atuam sobre os muros, mas que usam de sua materialidade para contextualizar sua obra. Exemplo disso é o artista Alexandre Orion que contextualiza suas pinturas através de fotografias, espontâneas ou não, com situações do cotidiano da cidade. Nas fotografias ele explora a relação entre figura e fundo extrapolando a condição de suporte que o muro poderia ter. Em suas obras, a pintura é "retirada" de sua tela dando a impressão de que realmente é parte daquela cena, apesar da marcada ironia.

Por último, temos o muro em si como obra de arte. Nessa situação o muro é levado à abstração máxima em que tanto a sua função primeira, de ser barreira, quanto a sua função de ser suporte, estão ausentes. Aqui o próprio muro é a arte, apesar de continuar tendo as mesmas características físicas do muro convencional. Exemplos disso são as obras de alguns arquitetos que usam esse elemento como composição estética em seus edifícios. É o caso do arquiteto mexicano Luis Barragán, que explora tanto a forma, a textura e a cor das superfícies dos muros para completar suas casas. Nesse mesmo sentido de compreensão do muro, há também o escultor norte-americano Richard Serra, que cria formas murarias como expressão de sua arte. Sem entrar no mérito da discussão artística da obra, o muro aqui está sendo usado de sua forma mais sublime, completamente abstraída do conceito de barreira.

É claro que, mesmo como objeto estético, o conceito de barreira poderá sempre ser colocado, entretanto o interesse deste trabalho é justamente deixar claro que a ideia que se tem desse elemento físico é dependente da relação tida com ele. Ou seja, a 
intenção é de retirar deste elemento o peso ideológico que lhe é determinado, principalmente no que diz respeito ao pensamento arquitetônico e ao longo do século $\mathrm{XX}$. 


\section{REFERÊNCIAS BIBLIOGRÁFICAS}

AGREST, Diana; GANDELSONAS, Mario. "Semiótica e arquitetura: consumo ideológico ou trabalho teórico." In: Uma nova agenda para arquitetura, por Kate NESBITT, 129-141. São Paulo: Cosac Naify, 2006.

AUGÉ, Marc. Não Lugares: Introdução a uma antropologia da supermodernidade. $9^{\mathrm{a}}$. Tradução: Maria Lúcia Pereira. Campinas, SP: Papirus, 2012.

BOURRIAUD, Nicolas. Estética Relacional. Tradução: Denise Bottmann. São Paulo, SP: Martins, 2009.

FREUD, Sigmund. A Interpretação dos Sonhos. Tradução: Renato Zwick. Vol. 1. Porto Alegre: L\&PM, 2013.

MUMFORD, Lewis. A Cidade na História. $3^{\mathrm{a}}$. São Paulo, SP: Livraria Martins Fontes Editora, 1991. 